\title{
Dietary effects on fitness in captive-reared Hawaiian tree snails
}

\author{
Evan Strouse $^{\text {Corresp., } 1}$, Melissa Price ${ }^{1,2}$, David Sischo $^{3}$ \\ ${ }^{1}$ Department of Natural Resources and Environmental Management, University of Hawai'i, Honolulu, Hawai'i, United States \\ ${ }^{2}$ Sherman Hall, University of Hawai'i, Honolulu, Hawai'i, United States \\ 3 Department of Land and Natural Resources, Division of Forestry and Wildlife, Honolulu, Hawai' $i$, United States \\ Corresponding Author: Evan Strouse \\ Email address: evanstrouse7@gmail.com
}

The native terrestrial snail fauna of the Hawaiian Islands faces numerous threats that have led to severe range reductions, population declines, and extinction of species. With the continued declines of many wild populations, a crucial component of preserving Hawaiian terrestrial snail biodiversity is through captive rearing programs, like that implemented by the Hawai'i Department of Land and Natural Resources Snail Extinction Prevention Program. Rare and endangered tree snails in the family Achatinellidae, which feed on epiphytic microbial communities, are maintained in captivity with a diet that includes native vegetation brought in from nearby forests, as well as a cultured fungus, originally isolated from native host trees. Recent mortality events in lab populations have been attributed to wild-gathered vegetation. These events have increased interest in developing a completely manufactured or cultured diet that would eliminate the need for exposure to wild-gathered plants. This study compared survival and egg production in Auriculella diaphana provided with lab-cultured fungus, and those provided with wild vegetation. We compared the number of eggs laid and number of deaths among three treatments: (1) wild collected vegetation only; (2) wild vegetation supplemented with laboratory-cultured fungus; and (3) laboratory cultured fungus only. Mortality did not significantly differ among treatments, but the number of eggs laid was significantly higher in snails provided wild vegetation and cultured fungus $(F=24.998 ; P<0.001)$, compared with those provided with only wild vegetation ( $t=1.88, P=0.032$ ) or only cultured fungus ( $t=4.530, P=0.004)$. Our results suggest: (1) the existing strain of cultured fungus alone is not sufficient to maintain captive-reared snail populations; (2) the additional energy or calcium provided by the cultured fungus appears to enhance egg reproduction in captive-reared populations; (3) the presence or absence of live vegetation influences snail behavior, including aestivation and egg laying. These results highlight the importance of ongoing research to culture additional species of fungi at a rate that could support captive-reared populations, as the 
diversity of fungi present in wild epiphytic microbial communities may be important for snail reproductive health. 


\section{Dietary Effects On Fitness in Captive-Reared Hawaiian Tree Snails}

2 Evan L. Strouse ${ }^{1}$, Melissa R. Price ${ }^{1,3}$ David R. Sischo ${ }^{2}$

$3{ }^{1}$ Department of Natural Resources and Environmental Management, University of Hawai' $i$,

4 Honolulu, Hawai'i, USA

$5 \quad{ }^{2}$ Department of Land and Natural Resources, Division of Forestry and Wildlife, Honolulu,

6 Hawai'i, USA

7 3Sherman Hall, 1910 East West Rd., Honolulu, HI 96822; fax: (808) 956-6539

8 (808) 539-7300, pricemel@hawaii.edu

10 Abstract

11 The native terrestrial snail fauna of the Hawaiian Islands faces numerous threats that have led to

12 severe range reductions, population declines, and extinction of species. With the continued

13 declines of many wild populations, a crucial component of preserving Hawaiian terrestrial snail

14 biodiversity is through captive rearing programs, like that implemented by the Hawai' ${ }^{\prime} \mathrm{i}$

15 Department of Land and Natural Resources Snail Extinction Prevention Program. Rare and

16 endangered tree snails in the family Achatinellidae, which feed on epiphytic microbial

17 communities, are maintained in captivity with a diet that includes native vegetation brought in

18 from nearby forests, as well as a cultured fungus, originally isolated from native host trees.

19 Recent mortality events in lab populations have been attributed to wild-gathered vegetation.

20 These events have increased interest in developing a completely manufactured or cultured diet

21 that would eliminate the need for exposure to wild-gathered plants. This study compared survival 
22 and egg production in Auriculella diaphana provided with lab-cultured fungus, and those 23 provided with wild vegetation. We compared the number of eggs laid and number of deaths

24 among three treatments: (1) wild collected vegetation only; (2) wild vegetation supplemented 25 with laboratory-cultured fungus; and (3) laboratory cultured fungus only. Mortality did not 26 significantly differ among treatments, but the number of eggs laid was significantly higher in 27 snails provided wild vegetation and cultured fungus ( $F=24.998 ; P<0.001)$, compared with those 28 provided with only wild vegetation $(t=1.88, P=0.032)$ or only cultured fungus $(t=4.530, P$ $29=0.004)$. Our results suggest: (1) the existing strain of cultured fungus alone is not sufficient to 30 maintain captive-reared snail populations; (2) the additional energy or calcium provided by the 31 cultured fungus appears to enhance egg reproduction in captive-reared populations; (3) the 32 presence or absence of live vegetation influences snail behavior, including aestivation and egg 33 laying. These results highlight the importance of ongoing research to culture additional species 34 of fungi at a rate that could support captive-reared populations, as the diversity of fungi present in wild epiphytic microbial communities may be important for snail reproductive health.

\section{Introduction}

38 Under threat from a variety of disturbances, such as climate change and introduced species, imperiled animals and plants are increasingly brought to ex situ facilities for captive propagation as a hedge against extinction (Snyder et al.,1996). Despite immediate protection from the in situ

41 drivers of extinction, ex situ captive propagation of endangered species faces many challenges

42 including, but not limited to, the maintenance of genetic diversity, overcoming genetic and 43 behavioral adaptation to captivity, the creation of appropriate diets, as well as exposure to and 44 transmission of diseases and parasites (Ralls and Meadows, 2001; Price et al. 2015). For many 
45 species, information on natural history is lacking, and thus basic husbandry practices must be

46 tested and developed either on dwindling populations of endangered species, or on proxy species

47 with more stable populations.

49 The Hawaiian Islands once hosted more than 750 species of terrestrial snails (Cowie et al., 1995). This remarkable diversity occurring over such a small land area arguably makes these islands one of the greatest land-snail hot-spots on earth. Hawaiian terrestrial snails or "kāhuli", once ubiquitous across multiple islands, were the inspiration for Hawaiian chants and storytelling, denoting romance and good omens, and were associated with the cool mists of the mountain forests (Sato et al., 2018). Despite their abundance and relevance to local culture and lore, during the last century threats including shell collection, habitat loss, climate change and the introduction of invasive predators, have decimated this fauna (Hadfield, 1986; Solem, 1990;

57 Hadfield, Miller and Carwile, 1993; Hadfield and Saufler, 2009; Holland, Montgomery and 58 Costello, 2010, Yeung and Hayes, 2018; Gerlach, 2020). Most of the species persisting are now only found in small portions of their historical ranges, with many species requiring ex situ captive propagation to prevent extinction. One subfamily, Achatinellinae, has been the focus of conservation efforts, including captive rearing, for over 30 years (Hadfield, Holland and Olival, 2004). Snails in this subfamily have

64 long lifespans, late maturity, and produce a single offspring per birth, making them highly 65 susceptible to extinction (Hadfield, 1986; Hadfield and Miller, 1989; Hadfield, Miller and 66 Carwile, 1993). Due to extreme declines the entire genus Achatinella, endemic to O`ahu, as well 67 as two species of Partulina endemic to Lana'i, and one species of Newcombia endemic to Maui, 
68 have been listed as Endangered under the U.S. Endangered Species Act (U.S. Fish and Wildlife

69 Service, 1981; U.S. Fish and Wildlife Service, 2016), while many other species across the 13

70 families present in the islands remain unlisted but extremely imperiled.

71

72 To support conservation efforts, the Snail Extinction Prevention Program (SEPP), was

73 established by the Hawai'i Department of Land and Natural Resources. One strategy of the

74 program is to use captive propagation to safeguard species from extinction, maintain

75 evolutionary potential, and generate individuals for reintroduction to protected areas in the wild

76 (Price et al. 2021), Currently, the SEPP captive rearing facility maintains populations of 38

77 species in eight genera, from five islands. The captive snails are housed in population-specific

78 terrariums inside environmental chambers that control relative humidity, temperature, light, and 79 simulated rain.

80

81 In the wild, tree snails feed on diverse epiphytic fungi that grow on native plants (Kobayashi and

82 Hadfield, 1996; O’Rorke et al., 2014; Price et al., 2017). Captive-reared tree snails are provided

83 fresh leafy branches of native plants from forested areas on $\mathrm{O}^{`}$ ahu. In addition, the snail diet is

84 supplemented with a lab-cultured fungus in the genus Cladosporium. This is a naturally

85 occurring biofilm component isolated from wild leaves and detected in fecal samples of wild

86 snails (O'Rorke et al., 2014). The fungi are inoculated on potato-dextrose agar and infused with

87 calcium carbonate powder to support shell growth. Prior research has demonstrated that some

88 snail species grow at a faster rate when supplemented with lab-cultured Cladosporium sp.

89 (Kobayashi and Hadfield, 1996). 
91 Recent mortality events above baseline levels in laboratory populations of Hawaiian tree snails

92

were attributed to a possible pathogen introduction, or exposure to toxicants or environmental toxins (Price et al. 2015; Sischo et al., 2016, Sischo et al., in prep). One of the main routes for pathogen introduction, or toxicant/toxin exposure in the laboratory is through the continued collection and use of leaves from the wild to feed captive-reared snails. Fresh vegetation is provided to captive-reared snails bi-weekly. Snails in the laboratory are maintained in high densities, and contaminated vegetation has the potential to introduce disease or parasites that could quickly spread within, and potentially among, terrariums. Furthermore, diets containing native vegetation preclude zoos and other institutions outside of Hawai 'i from participating in Hawaiian land snail conservation. This is problematic as Hawai' $\mathrm{i}$ is prone to natural disasters such as hurricanes and tsunamis. The disbursement of critically imperiled snail species amongst multiple institutions outside of the islands, eliminates the proverbial all eggs in one basket scenario. The International Partula Program, rears rare snail species in the genus Partula from the South Pacific region in participating zoological societies and research institutions across Europe and the United States (Pearce-Kelly, 1997). Their strategy of spreading vulnerable populations among many institutions has proven successful at preventing extinctions and serves as a model for our efforts here in Hawai' $i$. However, one of the keys to their success has been the development of a manufactured diet, allowing snails from islands in the South Pacific to be reared anywhere in the world (Clarke, 2019). Similarly, Gilbertson et al. 2019 describes captive rearing success with the endangered ovate amber snail Novisuccinea chittenangoensis, after optimizing a captive diet that includes dried leaves of preferred plants. Moving forward, it is critical for our conservation efforts here in Hawai' $i$ to develop and test dietary options that increase reproduction and survival and are not dependent upon fresh native vegetation. 
115 As a foundational step in this effort, in this study we compared the mortality and egg production 116 of captive tree snails provided with a diet of cultured fungus, with those fed on native vegetation,

117 to elucidate how the diet of the snails affects survival and egg production. If snails provided with

118 a cultured or manufactured diet could maintain fitness equivalent to snails fed on wild-gathered

119 vegetation, then Hawaiian tree snails could be reared anywhere in the world, with a reduced 120 potential for pathogen introduction or exposure to manmade toxicants such as herbicide etc., and 121 toxins such as secondary metabolites of naturally occurring bacteria and fungi.

Materials \& Methods

124 We observed the number of eggs laid and mortality in adult snails collected from wild 125 populations and captive-reared over a period of 13 weeks in the captive rearing facility run by 126 the Snail Extinction Prevention Program. The focal species selected for the study, Auriculella 127 diaphana, is a native tree snail in the subfamily Auriculellinae, a sister subfamily to that of 128 Achatinellinae. The subfamily Achatinellinae contains all of the Hawaiian land snails listed as 129 Endangered under the US Endangered Species Act of 1973 (Holland and Hadfield, 2004), but 130 low numbers in all remaining species, as well as low fecundity and long maturity times, do not 131 allow for efficient evaluation of the impact of diet on fitness. Auriculella diaphana was selected 132 as a proxy for these closely related endangered species, due to an epiphytic diet similar to 133 endangered snails in the Achatinellinae subfamily (Pilsbry, Hyatt and Cooke, 1912, O’Rorke et al., 134 2014, Price et al., 2017). Further, oviparity in A. diaphana allowed for timely comparison of 135 fecundity among treatments. However, as eggs of $A$. diaphana take over one month to hatch, 136 overall reproductive success was beyond the scope of this study; egg production was used to 
137 evaluate the potential impact of the diet treatment on reproductive success.

138

139 Sample collection. A total of 120 A. diaphana were collected from the Ko'olau mountains on

140 the island of $\mathrm{O}^{`}$ ahu, Hawai'i, USA under the supervision of the Department of Land and Natural

141 Resources - Snail Extinction Prevention Program (SEPP). The snails were hand-collected from

142 multiple trees and shrubs across the range of the study population. Because some achatinellid

143 species have very small ranges, in some instances spending their whole lives in a single tree

144 (Hadfield and Saufler 2009), distance was used as a proxy for genetic diversity. Host trees at this

145 particular site were all non-native species to Hawai'i, including Cestrum nocturnum, Bischofia

146 javanica, Coffea arabica, and Hedychium coronarium. All snails selected were adults (sexually

147 mature). Adults were identified by a lip formation on the shell aperture indicative of sexual

148 maturity (Pilsbry and Cooke 1912-1914). Once collected, the snails were immediately

149 transported to the captive-rearing facility in small plastic containers.

150

151 Acclimation period. At the laboratory, snails were randomly placed in four large clear plastic

152 terrariums, at a density of 30 individuals per terrarium, for a three-week period. This allowed the

153 snails to acclimate to their new environment, prior to initiating the study. During acclimation all

154 snails were offered both the wild vegetation and lab-cultured fungus. While acclimating, all eggs

155 deposited in the terrariums were removed during cleaning and were not included in the study.

156

157 Setup. Terrariums were housed in a single Caron brand insect-growth environmental chamber

158 (Model 6025-1). Day and nighttime temperature and relative humidity were controlled to mimic

Peer] reviewing PDF | (2020:08:51910:3:0:CHECK 3 Jun 2021) 
159 wild conditions $\left(21^{\circ} \mathrm{C}\right.$ and $80 \%$ relative humidity during day simulation, and $20^{\circ} \mathrm{C}$ and $90 \%$

160 relative humidity during night simulation). An automatic misting system simulated rain

161 periodically through the lid of the terrarium. A 12-hour day and 12-hour night cycle was created,

162 with florescent chamber lights, to simulate the average photoperiod in the Hawaiian Islands.

163 Throughout the study, each terrarium was cleaned and censused once every two weeks. This

164 process involved removing the old vegetation and/or cultured fungus and replacing it with fresh

165 material, steam sterilizing the cage in a dishwasher, accounting for all adult snails, checking for

166 deaths, and searching for eggs. To confirm that the presence or absence of vegetation within

167 different treatments did not alter the ambient temperature and relative humidity within terraria, a

168 temperature and humidity data logger was placed within one terrarium of each treatment, and no

169 differences were detected.

170

171 Experimental Design. A total of ninety individuals were selected from the acclimated snails and

172 randomly assigned to three feeding treatments for ten weeks: (1) wild collected vegetation; (2)

173 wild vegetation and laboratory-cultured fungus; (3) laboratory cultured fungus only. Vegetation

174 for all laboratory snails at the SEPP lab is collected weekly from several field sites in the

175 Waianae and Koolau mountain ranges on $\mathrm{O}^{`}$ ahu. This fresh vegetation was provided to all

176 treatments, except the fungus only treatment, and consisted of native species in the following

177 percentages $80 \%$ Metrosideros polymorpha and a mixture of approximately $20 \%$ of Freycinetia

178 arborea, Nestegis sandwicensis, Pisonia umbellifera, Psydrax odorata, and Antidesma

179 platyphyllum. Each treatment consisted of three terrariums with 10 snails per terrarium. All of

180 the terrariums were cleaned and checked for deaths and eggs laid as described above. The eggs

181 and dead snails were removed from cages during each cleaning and recorded. Fecundity was

Peer) reviewing PDF | (2020:08:51910:3:0:CHECK 3 Jun 2021) 
182 measured as the number of eggs produced per adult per two weeks. Differences in the number of

183 eggs laid among treatments was assessed with an analysis of variance (ANOVA) using JASP,

184 version 0.9.2. If a difference among treatments was detected with an ANOVA, $t$-tests were run to

185 identify which treatments differed from others. Additionally, a repeated measures analysis of

186 variance test was performed using JASP to determine if egg production in each cage changed

187 significantly over time.

188

189 Results

190 There were significant differences in egg production among all treatments $(F=24.998 ; P$

$191<0.001)$ (Figure 1). Snails in Treatment 1 (vegetation and fungus) produced 2.4 times more eggs

192 (241 eggs laid, average of 8 eggs/snail) than snails in Treatment 2 (vegetation alone) (102 eggs

193 laid, average of 3.4 eggs/snail) $(t=1.88, P=0.032)$. Snails in Treatment 1 produced 30.1 times

194 more eggs than Treatment 3 (fungus alone) (8 eggs laid, average of .27 eggs/snail) $(t=4.530, P$

$195=0.004)$. Snails in Treatment 2 (vegetation alone) produced 12.8 times more eggs than Treatment

1963 (fungus alone) $(t=2.642, P=0.046)$. The snails in Treatment 3 (fungus alone) appeared to be

197 less active throughout the study and were observed to be sealed to the sides or top of the cage

198 when cages were cleaned, a behavior referred to as "aestivation". There was no significant

199 difference in egg production over time $(F(8,3)=2.150, P=0.120)$.

200

201 Overall survivorship was high in all treatments with only four deaths total during the study. Of

202 these deaths, three of them occurred in Treatment 1 (vegetation and fungus), and one occurred in

203 Treatment 2 (vegetation). There was no mortality in Treatment 3 (fungus alone).

Peer) reviewing PDF | (2020:08:51910:3:0:CHECK 3 Jun 2021) 


\section{Discussion}

206 Maintaining low mortality, as well as high fecundity, in captive-reared populations is particularly

207 important for endangered species across taxa. Snail species in the subfamily Achatinellinae do

208 not reach maturity until three to five years of age and produce fewer than ten offspring per year

209 (Hadfield and Miller 1989; Hadfield and Mountain 1980; Price et al. 2015). Therefore,

210 optimizing captive-rearing conditions is crucial for Hawaiian tree snail conservation, as small

211 differences in survival and reproduction can have large impacts on the long-term viability of

212 captive-reared colonies. The primary objective of this study was to compare survival and egg

213 production between captive-reared snails fed a diet of a natural epiphytic biofilm on leaves

214 collected from native forests, and captive-reared snails fed a diet of lab-cultured fungus. The

215 number of eggs laid was significantly higher in snails provided a diet of both cultured fungus and

216 wild-gathered leaves, than in snails provided a diet of leaves alone or fungus alone. Further,

217 snails provided with only native vegetation laid more eggs than snails provided with lab-cultured

218 fungus alone. These results suggest that a diet consisting of diverse microbes, like that occurring

219 on native vegetation, may be important for snail reproduction as both treatments including

220 vegetation yielded more eggs than snails provided with fungus alone. Additionally, because

221 snails offered vegetation and fungus laid more eggs than the other two treatments, it is possible

222 that bulk (defined here as fungal mass) and or calcium supplementation may be important factors

223 in snail reproduction in captivity. Snails also readily consume the potato dextrose agar, which

224 may increase reproduction simply by providing more calories (O'Rorke et al. 2016). Another

225 potential explanation is that surface cues on leaf or branch substrates may be necessary for egg

226 production.

Peer) reviewing PDF | (2020:08:51910:3:0:CHECK 3 Jun 2021) 
228 While the mortality in this experiment was minimal, the length of the study period may not have

229

230

231

232

233

234

235

236

237

238

239

240

241

242

243

244

245

246

247

248

249

revealed long-term differences in survival among treatments. Each time the snails were censused, little to no activity was seen in the snails in Treatment 3 (fungus alone). In contrast, snails in the other two treatments were more active throughout the trial, moving around the cage. The aestivation behavior in the snails fed only the lab-cultured fungus may be a stress response that would result in higher mortality over a longer interval due to long-term sub-lethal stress. It is possible that snails in the fungus-only treatment were less active due to a lack of suitable substrate rather than an insufficiency in their diet. Relative humidity and temperature were uniform throughout the cages; however, leafy branches may hold more surface moisture than an empty plastic cage. It is possible that the presence or absence of plant material impacts snail behavior that in turn impacts reproduction. However, a previous study of Auriculella diaphana comparing differences in egg production between snails maintained on native vegetation verses non-native vegetation (Holland, Chiaverano and Howard, 2017) found that snails fed native vegetation had 20.5-fold higher number of eggs produced than snails maintained on non-native vegetation. Non-native plants may host less diversity or less mass of native fungal species but would likely provide suitable substrate for other behaviors. These studies highlight the critical need to evaluate nutrient and energy needs for captive-reared snails, and the potential for other epiphytic fungal species derived from native plants to support thriving captive populations. The results of this study complement previous work suggesting the current diet for captivereared snails, which includes wild vegetation in addition to lab-cultured fungus, is optimal to maximize reproduction and survival during captive-rearing compared to diets consisting of 
250 cultured fungus or leaves alone. Previous studies have identified thousands of bacterial and

251 fungal operational taxonomic units that are on leaf surfaces and ingested by snails (O'Rorke et

252 al. 2014; Price et al. 2015). Our study may suggest that the single Cladosporium sp. cultured in

253 the laboratory is insufficient to support captive populations on its own, but its continued use as a

254 supplement to wild-collected vegetation is supported as beneficial, as previous studies have

255 suggested (Kobayashi and Hadfield, 1996). While this study was short in duration, it has been

256 particularly valuable in directing future lines of inquiry. Follow-up research should include: (1)

257 determining the nutrients associated with diverse epiphytic communities ingested by snails to

258 support the creation of a manufactured diet; (2) identifying which of the many epiphytic

259 microbes ingested by snails supports long-term survival and reproduction; (3) development of

260 methods to culture and grow additional fungal species at a rate that will support captive-rearing

261 of snails; (4) identifying which microbes produce secondary metabolites that may be toxic to

262 snails and associated with snail mortality, and if they vary in distribution, time, and density

263 geographically so they could be avoided; 5). whether the presence of substrate (such as leafy

264 branches in this study) impacts snail behavior that in turn impacts survival and reproduction.

265

\section{Conclusion}

267 Hawaiian land snail conservation currently relies on captive propagation to prevent extinction in 268

271 Further research regarding dietary impacts on captive snails, and the development of additional

272 varieties of cultured fungi, is timely and urgent since the risk of introducing a pathogen, parasite, 
273 toxin, or toxicant from vegetation collected from the wild has the potential to decimate captive 274 populations, potentially resulting in extinctions. Further, there are few, if any studies of 275 nutritional requirements to support the development of snail diets. If a completely manufactured 276 or cultured diet that supports snail growth and reproduction can be identified, the risk of 277 exposure could be minimized, and captive propagation of Hawaiian tree snails could then be 278 conducted anywhere in the world.

279

\section{Acknowledgements}

281 This research was supported by the Hawai 'i Department of Land and Natural Resources282 Division of Forestry and Wildlife, and the Snail Extinction Prevention Program. We also 283 appreciate the valuable input from members of the Wildlife Ecology laboratory at the University 284 of Hawai'i i at Mānoa.

\section{References}

Cowie R. H., Evenhuis N. L., Christensen C. C. 1995. Catalog of the Native land and Freshwater Molluscs of the Hawaiian Islands. The Netherlands: Backhuys Publishers

Clarke D. 2019. EAZA Best Practice Guidelines for Partula snails. European Association of Zoos and Aquariums 2019

Gerlach J., Barker G. M., Bick C. S., Bourchet P., Brodie G., Christensen C. C., Collins T., 
295

296

297

298

299

300

301

302

303

304

305

306

307

308

309

310

311

312

313

314 Hadfield M. G., Miller S. E., Carwile A. H. 1993. The Decimation of Endemic Hawaiian Tree 315

Meyer J., Meyer W. M., Richling I., Slapcinsky J. D., Winsor L., Yeung N. W. 2020. Negative impacts of invasive predators used as biological control agents against the pest snail Lissachatina fulica: the snail Euglandina 'rosea' and the flatworm Platydemus manokwari. Biological Invasions. 10.1007/s10530-020-02436-w.

Gilbertson C. R., Rundell R. J., Niver R. 2019. Determining diet and establishing a captive population of a rare endemic detritivore, the endangered Novisuccinea chittenangoensis (Pilsbry, 1908) (Pulmonata: Succineidae), Journal of Molluscan Studies, Volume 85(1): 41-47

Hadfield M. G., Mountain B. S. 1980. A field study of a vanishing species, Achatinella mustelina (Gastropoda, Pulmonata), in the Waianae Mountains of Oahu., Pacific Science. 34:345358.

Hadfield M. G. 1986. Extinction in Hawaiian achatinelline snails. Malacologia 67:67-81

Hadfield M. G., Miller S. E. 1989. Demographic studies on Hawaii’s endnagered tree snails: Partulina proxima. Pacific Science 43:1-16

Snails by Alien Predators. American Zoologist, 33(6):610-622 DOI:

Peer) reviewing PDF | (2020:08:51910:3:0:CHECK 3 Jun 2021) 
318 Hadfield M. G., Holland B. S., Olival K. J. 2004. Contributions of ex situ propagation and 319 molecular genetics to conservation of Hawaiian tree snails. Pages $16-34$ in M. Gordon and S. Bartol, eds. Experimental approaches to conservation biology. University of California Press, Berkeley.

Hadfield M. G., and Saufler J. E. 2009. The demographics of destruction: Isolated populations of arboreal snails and sustained predation by rats on the island of Molokai 1982-2006. Biological Invasions 11:1595-1609.

327

Holland B. S., Chiaverano L. M., Howard C. K. 2017. Diminished fitness in an endemic Hawaiian snail in nonnative host plants. Ethology Ecology \& Evolution, 29(3):229-240 DOI: $10.1080 / 03949370.2016 .1143406$

330

331 332 333 334 335 336
Holland B. S., Hadfield M.G. 2004. Origin and diversification of the endemic Hawaiian tree snails (Achatinellidae: Achatinellinae) based on molecular evidence. Molecular Phylogenetics and Evolution 32: 588-600.
Holland B. S., Montgomery S. L., Costello V. 2010. A reptilian smoking gun: First record of invasive Jackson's chameleon (Chamaeleo jacksonii) predation on native Hawaiian 
339 Kobayashi S., Hadfield M. G. 1996. An Experimental Study of Growth and Reproduction in the Hawaiian Tree Snails Achatinella mustelina and Partulina redfieldii (Achatinellinae). Pacific Science. 50(4):339

O’Rorke R., Cobian G. M., Holland B. S., Price M. R., Costello V., Amend A. S. 2014. Dining local: The microbial diet of a snail that grazes microbial communities is geographically structured. Environmental Microbiology. 17(5):1753-1764 DOI: 10.1111/14622920.12630

O'Rorke R., Holland B. S., Cobian G. M., Gaughen K., Amend A. S. 2016. Dietary preferences 351

Pearce-Kelly P., Clarke D., Walker C., and Atkin P. 1997. A conservation programme for the partulid tree snails of the Pacific region. Memoirs of the Museum of Victoria 56(2): 431433. 22: Achatinellidae. Academy of Natural Sciences, Philadelphia. 
359 Price M. R., Forsman Z., Knapp I., Toonen R. J., Hadfield M. G. 2021. Conservation of evolutionary potential in a rapidly declining subfamily of endangered Hawaiian tree snails (Achatinellinae: Achatinellidae). PeerJ, In Press.

362

363

364

365

366

367

368

369

370

371

372

373

374

375 Ralls K., Meadows R. 2001. Captive Breeding and Reintroduction. Encyclopedia of 376

377

378 Sato A. Y., Price M. R., Vaughan M. B. 2018. Kāhuli: Uncovering Indigenous Ecological an Ex Situ Population of Critically Endangered Hawaiian Tree Snails. PLoS One. 9(12): e114377.

Price M. R., Sischo D. R., Pascua M. A., Hadfield M. G. 2015. Demographic and genetic factors in the recovery of ex situ populations following a severe bottleneck in fifteen species of Hawaiian tree snails. PeerJ 3:e1406 DOI: 10.7717/peerj.1406

Price M. R., O’Rorke R., Amend A. S., Hadfield M. G. 2017. Diet selection at three spatial scales: Implications for conservation of an endangered Hawaiian tree snail. Biotropica 49:130-136. Biodiversity, volume 1. 
379

380

381

382

383

384

385

386

387

388

389

390

391

392

393

394

397 395 Hawaiian (Oahu) tree snails of the genus Achatinella as endangered species. Federal $396 \quad$ Register $46: 3178-3182$

Knowledge to Conserve Endangered Hawaiian Land Snails. Society and Natural

Resources 31(3):320-334 DOI: $\underline{\text { 10.1080/08941920.2017.1413695 }}$

Sischo D. R., Price M. R., Pascua M.., Hadfield M. G. 2016. Genetic and demographic insights into the decline of a captive population of the endangered Hawaiian tree snails Achatinella fuscobasis (Achatinellinae). Pacific Science 70(2) 133-141, DOI:10.2984/70.2.1

Snyder N. F. R, Derrickson S. R., Beissinger S. R., Wiley J. W., Smith T. B., Toone WD, Miller B. 1996. Limitations of captive breeding in endangered species recovery. Conservation Biology 10:338-348. DOI:10.1046/j.1523-1739.1996.10020338.x

Solem A. 1990. How many Hawaiian land snail species are left? And what we can do for them? Bishop Museum Occasional Papers 30:27-40

394 U.S Fish and Wildlife Service. 1981. Endangered and threatened wildlife and plants: Listing the 
398 U.S. Fish and Wildlife Service. 2016. Endangered and Threatened Wildlife and Plants;

399 Designation and No designation of Critical Habitat on Molokai, Lanai, Maui, and

$400 \quad$ Kahoolawe for 135 Species. Federal Register 81(61):17790-18110

401

402 Yeung N., Hayes K. 2018. Biodiversity and Extinction of Hawaiian Land Snails: How Many Are 403 Left Now and What Must We Do to Conserve Them-A Reply to Solem (1990). 2018.

404 Integrative and Comparative Biology 58(6):1157-1169 DOI:10.1093/icb/icy043 
Figure 1

A comparison of fecundity between each treatment of $A$. diaphana.

Each box-plot shows the average eggs laid per snail per every two weeks (represented as "x"). The minimum and maximum eggs laid per snail per two weeks for each treatment are represented by the numbered lines.

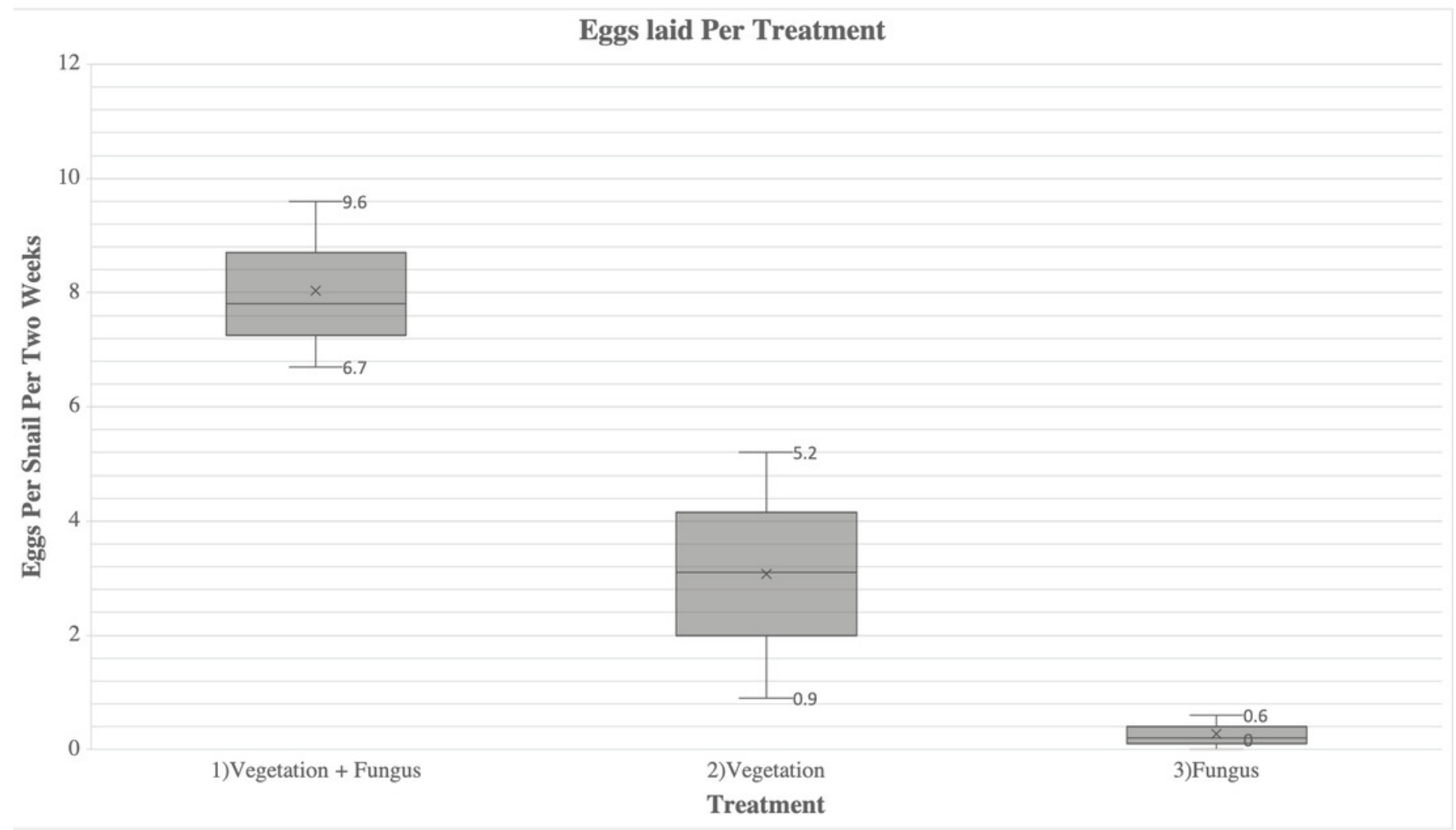

